\title{
Auction Revenue in the General Spiteful-Utility Model
}

\author{
Jing Chen \\ CS Department, Stony Brook University \\ Stony Brook, NY 11794, USA \\ jingchen@cs.stonybrook.edu
}

\author{
Silvio Micali \\ CSAIL, MIT \\ Cambridge, MA 02139, USA \\ silvio@csail.mit.edu
}

\begin{abstract}
It is well accepted that, in some auctions, a player's "true utility" may depend not only on the price he pays and whether or not he wins the good, but also on various forms of externalities, such as the prices paid by his competitors, and the identity and true value of the actual winner.

In this work, we study revenue generation in single-good auctions under a very general model of externalities: the General Spiteful-Utility Model. Specifically, we

- Put forward new revenue benchmarks and solution concepts;

- Design new mechanisms when some information about the players' externalities is known; and

- Analyze the revenue of the second-price mechanism when only the players have information about each other.
\end{abstract}

\section{Categories and Subject Descriptors}

[Theory of computation]: Algorithmic game theory and mechanism design

\section{Keywords}

externality; spitefulness; revenue; single-good auction; undominated strategy; light Bayesian setting

\section{INTRODUCTION}

In single-good auctions, the famous second-price mechanism guarantees revenue equal to the second highest true value in dominant strategies. This revenue guarantee is very attractive and does not require the mechanism to have any information about the players' true values. However, it only holds for players with classical utilities. The classical utility of a player $i$ is $c u_{i} \triangleq v_{i}-p_{i}$, if he wins the good, and $-p_{i}$ otherwise, where $v_{i}$ and $p_{i}$ respectively are $i$ 's value for the good and $i$ 's price.

Permission to make digital or hard copies of all or part of this work for personal or classroom use is granted without fee provided that copies are not made or distributed for profit or commercial advantage and that copies bear this notice and the full citation on the first page. Copyrights for components of this work owned by others than the author(s) must be honored. Abstracting with credit is permitted. To copy otherwise, or republish, to post on servers or to redistribute to lists, requires prior specific permission and/or a fee. Request permissions from Permissions@ acm.org.

ITCS'16, January 14-16, 2016, Cambridge, MA, USA.

Copyright is held by the owner/author(s). Publication rights licensed to ACM.

ACM 978-1-4503-4057-1/16/01 ...\$15.00.

DOI: http://dx.doi.org/10.1145/2840728.2840741.

\section{The General Spiteful-Utility Model.}

It has been widely recognized (see, e.g., $[29,7,30,19])$ that classical utilities are only "part of the story", and a player's "true utility" may also depend on various externalities, such as the prices paid by his competitors or the identity of the actual winner.

In this paper, we study auction revenue under a very general externality model: the general spiteful-utility (GSU) model. In this model, the utility of a player $i$ is

$$
u_{i}=c u_{i}-\sum_{j \neq i} \alpha_{i j} c u_{j}
$$

where each $\alpha_{i j}$ is a constant in $[0,1]$, referred to as $i$ 's utility exchange rate for player $j$. In other words, for all players $i$ and $j$, a monetary gain/loss of $x$ for $j$ translates into a corresponding loss/gain of $\alpha_{i j} x$ for $i{ }^{1}$ When all exchange rates are 0 , the players have classical utilities. When $\alpha_{i j}>0$, player $i$ is spiteful of player $j$.

(Note: Our results hold also when spitefulness is recursively defined, see Section 7.)

An important special case of the GSU model is when each player $i$ spites his opponents equally, but possibly differently from other players. That is, for each $i$, there exists a value $\alpha_{i}$ such that $\alpha_{i j}=\alpha_{i}$ for all $j \neq i$ (but $\alpha_{i}$ and $\alpha_{j}$ may be different if $i \neq j$ ). We refer to this important case as the individually uniformly spiteful model.

The GSU model is not a mere syntactic generalization of the classical utility model, but is very natural and meaningful. In particular, it may endogenously model the players' strategic interests in their interactions after or outside the auction. For instance, let the good be a large oil field and players $i$ and $j$ two oil companies, which will continue to compete fiercely after the auction. Assume now that $j$ wins the oil field for a minimal price, and $i$ pays nothing at all. Then, although $i$ 's classical utility is 0 , his 'true' utility would actually be negative, because he will 'suffer' in the future, as $j$ will use his newly acquired resource against $i$. However, if $j$ paid a very high price for the oil field, then $i$ 's suffering would be amply mitigated, as $j$ would have less net resources to use against $i$ in the future.

\section{Related Work on Auctions.}

Up to now, in auctions, mostly special cases of the GSU model have been studied. In particular, [35] experimen-

\footnotetext{
${ }^{1}$ Although utility exchange rates $>1$ could be justified in some extreme settings, we prefer to assume that a player strictly prefers receiving one dollar himself to having a competitor lose one dollar or less.
} 
tally studies auctions and other games in which the utilityexchange rates are severely restricted $;^{2}[43]$ studies auctions where all exchange rates are the same; and there is another work which studied auctions where each player $i$ has the same number of non-zero utility-exchange rates and all such rates are equal, but due to an unfixable problem in the analysis the paper has been essentially retracted ${ }^{3}$ and the authors have asked the paper not to be cited.

The economic literature contains many studies of auctions where a player's utility depends on (besides his own valuation and price) just the valuation, or the price, or the identity of the actual winner of the good. Games other than auctions have also been studied under various models of externalities. We provide a more detailed discussion about this literature in Section 2.

To the best of our knowledge, [19] is the only work in the literature studying an auction mechanism in the GSU model; yet, as pointed out by the authors themselves, their mechanism only works when the utility exchange rates are "extremely small": namely, when $\alpha_{i j}=O\left(1 / n^{3}\right)$ for any $i, j$, where $n$ is the number of players.

In sum, it is fair to say that, despite its meaningfulness, the general spiteful-utility model remains vastly understudied in auctions.

\section{Our Goal.}

We aim at starting the study of auction revenue in the general spiteful-utility model, without any restrictions. By contrast, the auction mechanism of [19] focuses on social welfare. Accordingly, their paper aims at overcoming the players' spitefulness, ${ }^{4}$ so as to incentivize them to bid almost truthfully. We instead aim at leveraging the players' spitefulness, so as to incentivize them to place bids higher than their true valuations. Again, in [19], the exchange rates are assumed to be extremely small; while by contrast, our results hold for all (positive) exchange rates.

\section{Participation.}

Generating revenue is trivial when a mechanism is able to impose arbitrarily high prices to 'unwilling players'. An important principle in designing revenue mechanisms is to allow players to 'opt out' of the auction without paying anything and without receiving the good. We do follow this principle: all mechanisms studied allow a player to opt out by bidding 0 . In auctions without externalities, the utility of a player opting out is 0 . However, this may not be true for a spiteful player. Indeed, if a player $i$ opts out, and the good is allocated at price 0 to a player spited by $i$, then, without any fault of the mechanism, $i$ 's utility will be negative.

\section{Potential and Challenges of the GSU model.}

Intuitively, an auction with spiteful players is 'more competitive than a classical one'. Thus, a properly designed

\footnotetext{
${ }^{2}$ Namely, there is a common parameter $\lambda$ and each player $i$ has his own parameter $a_{i}$ (positive if the player is spiteful, and negative if he is 'altruistic'), so that $i$ 's utility exchange rate for an opponent $j$ is $\frac{a_{i}+\lambda a_{j}}{1+\lambda}$.

${ }^{3}$ We thank an anonymous reviewer for pointing this out.

${ }^{4}$ A player $i$ is spiteful towards another player $j$ if $\alpha_{i j}>0$, and altruistic if $\alpha_{i j}<0$. Actually, [19] also wish to overcome the players' altruism. But, aiming at maximizing revenue, we focus solely on spitefulness.
}

mechanism may be able to translate this additional competition into additional revenue. To realize this potential, however, several challenges must be met. Most importantly, to act rationally in a mechanism, spiteful players in general need to know their own utility functions exactly, which they do only in auctions of complete information, where the true valuation profile is common knowledge among the players. Thus, analyzing classical and new mechanisms with spiteful players less informed about each other requires the adoption of new and appropriate solution concepts.

\section{Results.}

We show that the slightest information about the players' exchange rates can be extremely powerful, even when the players have no information about the valuations and exchange rates of their opponents. Informally, we prove that

\section{A mechanism knowing a positive lower bound about the} exchange rate of just two players can extract arbitrarily high revenue in strictly dominant strategies.

When the mechanism has no information about the spiteful players, they must have some information about each other, as argued above, in order to be able to act rationally. The first setting to consider is one of complete information. Indeed, this extreme case allows us to study how spiteful players behave in the GSU model when they know their utility functions exactly. For auctions of complete information we exactly characterize the players' weakly undominated strategies in the classic second-price mechanism in the GSU model and prove that

2. The revenue obtainable by the second-price mechanism in weakly undominated strategies is at least the secondhighest virtual value, and this lower bound is tight.

Above, the second-highest virtual value, a new benchmark for the GSU model, is always greater than or equal to a half of the second highest true value, less than or equal to the second highest true value when there are at least three players, but can be much larger than the latter when there are two players. Furthermore, for the same setting, we prove that

3. The revenue obtainable by the second-price mechanism in strategies surviving two levels of elimination of weakly dominated strategies is at least the highest virtual value.

This lower bound is actually tight as well.

Settings of complete information are of course quite ideal. We thus consider the Light Bayesian Setting. In this setting, essentially, the true value of each player $i$ is independently drawn from a distribution $\mathcal{D}_{i}$ and each player $i$ individually knows $\mathcal{D}_{-i}$. (Note that the Light Bayesian Setting is much weaker and more realistic than the traditional common prior model, where the distribution profile $\left(\mathcal{D}_{1}, \ldots, \mathcal{D}_{n}\right)$ is common knowledge to the players, and often to the mechanism as well!) Here we prove that

4. In the individually uniformly spiteful model, the expected revenue of the second-price mechanism, in Bayesian undominated strategies, can be smaller than the expectation of the second-highest valuation, but is never smaller than a half of it. 
Above, implementation in Bayesian undominated strategies is a new and very compelling solution concept put forward by us. We consider this as a conceptual contribution that will prove useful in mechanism design in the GSU model.

\section{In Sum.}

We show that spitefulness can yield very high revenue when a mechanism designer has even a small amount of information about the exchange rate of the players, or when the players have a lot of information about each other, but otherwise can lead to much less revenue than when the players have classical utilities (e.g., a half in the worst case). For an auctioneer, the latter information, although demoralizing, is useful to know. Since the auctioneer in general has no way to tell whether the players have externalities or not, he is better off knowing how much revenue he is risking losing if he decides to adopt a classical mechanism like the second-price. And he may actually be encouraged to investigate totally new mechanisms designed to take advantage of this difficult setting. One step at a time. We believe mechanism analysis and design in the GSU model to be challenging, meaningful, and fun.

\section{ADDITIONAL RELATED WORKS}

\section{Generating Revenue in Auctions with Externalities.}

There have been many works on financial externalities in auctions; see, e.g., $[16,8,15,17,25,37]$. In general, they assume that the losers' utilities in an auction depend on the payment of the winner, but not on the true value or the identity of the winner. Moreover, the parameters for measuring externality have the same values for all players. In [36], the author studies financial externalities among players with regular i.i.d. values, where different players have different externality parameters. The author allows each player to have a non-negative gain from the winner's value - rather than a loss as in our model - and characterizes the optimal Bayesian mechanisms.

In another line of works $[29,30,28,44,1,31]$, the externalities in auctions come from the identity of the winner rather than his payment, and may not be the same among the players.

In [18] and [21] the authors consider models where the players hold "shares" in the goods, so that the losers receive positive externality from the winner's utility. Recall that in our model the players are spiteful and the loser receives negative externality from the winner's utility.

Most of the works mentioned above have focused on analyzing the revenue performance of the first-price mechanism and/or the second-price mechanism (sometimes with reserve prices), under various equilibrium-based solution concepts. In $[29,30]$ the authors studied mechanism design for singlegood auctions to generate revenue, and characterized the optimal mechanisms in complete information as well as Bayesian settings. As mentioned above, the externality model they use is identity-based and does not depend on the players' payments.

Finally, the above models of externalities are one sided - only the losers have externality from the winner and not viceversa. This is without loss of generality for their studies, since in both the second-price and the first-price mechanisms the loser does not get any good and does not pay anything, and in the identity-based model the value received by the losers is 0. By contrast, our model allows the possibility that the mechanism gives all players positive prices, and thus externalities are defined for both the winner and the loser.

\section{Externalities in Other Contexts.}

As mentioned, in [19] the externality model is the same as ours, but the major goal there is to generate social welfare, and their mechanism works when the exchange rates are extremely small. There are many other studies on games with externalities, but the contexts, models, and goals are all quite different from ours. Thus we do not elaborate on them here, and only mention several examples. In [33, 4, 13] the authors mainly focus on the computational complexity for finding/approximating desired outcomes when there are externalities. In $[40,20,24,32,23,26,41,14]$ the authors examine sponsored-search auctions and incorporate the externalities affecting the probability for an advertisement to receive a click, caused by other advertisements shown on the same webpage. In [22] and [10] the authors study externalities raised on social networks, in [2] and [42] externalities in congestion games, in [6] network formation with externalities, and in $[5,9,45,38]$ coalition formation with externalities. Finally, [34] is on experimental study, [12] on traffic routing, and a detailed review of the literature can be found in [11].

\section{OUR FIRST RESULT}

Given a mechanism, letting $S_{i}$ be the set of available strategies of each player $i$, a strategy $s_{i} \in S_{i}$ is a strictly dominant strategy if $u_{i}\left(s_{i}, s_{-i}\right)>u_{i}\left(s_{i}^{\prime}, s_{-i}\right)$ for all strategy subprofiles $s_{-i} \in S_{-i}$ and all strategies $s_{i}^{\prime} \in S_{i} \backslash\left\{s_{i}\right\}$. Notice that if a strictly dominant strategy exists, then it must be unique.

Below, we construct a normal-form mechanism, $M_{P}$, that takes an arbitrarily high number $P$ as an input and generates revenue at least $P$ at the strictly dominant strategy profile. Surprisingly, the mechanism $M_{P}$ never sells the good, but generates revenue solely by leveraging the players' spitefulness.

Of course, we do not consider never selling the good as an 'advantage' (particularly when the auctioneer wishes to guarantee a minimum of social welfare). But we consider it important to highlight how much revenue potential lies in knowing the players' spitefulness. Actually, a minimum amount of such knowledge suffices. Indeed, to use $M_{P}$, the auctioneer need only know $\ell, i$ and $j$, such that $0<\ell \leq \alpha_{i j}$, but nothing else about the players' values or exchange rates.

Letting, without loss of generality, $i=1$ and $j=2$; and recalling that the number of players is $n$, our mechanism $M_{P}$ works as follows.

\section{Mechanism $M_{P}$}

Each player $i$ announces $b_{i} \in\{0,1\}$, where 0 means "opting out" and 1 means "participating".

The good is unsold and each player $i \notin\{1,2\}$ receives a payment equal to $b_{i}$. The prices of players 1 and 2 are as follows:

If $b_{2}=0$, then player 1 receives a payment equal to $b_{1}$ and player 2 receives 0 . 
If $b_{1}=0$ and $b_{2}=1$, then player 2 receives $\frac{P+n}{\ell}$ and player 1 receives 0 .

If $b_{1}=b_{2}=1$, then player 1 pays $P+n-1$ and player 2 receives $\frac{1}{2}$.

We have the following theorem, whose proof is provided in the appendix.

THEOREM 1. For any $n \geq 2$ and $P>0$, in mechanism $M_{P}$, it is strictly dominant for each player to announce 1; and the revenue of $M_{P}$ under the strategy profile $(1,1, \ldots, 1)$ is at least $P$.

\section{Remark.}

We stress that $M_{P}$ making a big payment is just a threat: at the unique dominant-strategy equilibrium, he only receives payments from the players. Yet, as proven by the extraordinary revenue performance that it entails, such a (credible) ability cannot be taken for granted.

\section{OUR SECOND RESULT}

Now we consider the extreme, yet fundamental, case where the players have complete information about each other's valuation and exchange rates.

To begin with, the second-price mechanism naturally allows players to 'opt out': if a player bids 0 , then he is considered non-participating and the mechanism is run on the remaining players. It is not hard to see there is no (strictly or weakly) dominant strategies for players with externalities, thus the solution concept we consider is undominated strategies:

A strategy $s_{i} \in S_{i}$ is weakly dominated by $s_{i}^{\prime} \in S_{i}$ if

(a) $u_{i}\left(s_{i}, s_{-i}\right) \leq u_{i}\left(s_{i}^{\prime}, s_{-i}\right)$ for all strategy subprofiles $s_{-i} \in S_{-i}$, and

(b) $u_{i}\left(s_{i}, s_{-i}\right)<u_{i}\left(s_{i}^{\prime}, s_{-i}\right)$ for at least one strategy subprofile $s_{-i} \in S_{-i}$.

If $s_{i}$ is not weakly dominated by any other strategy, then it is undominated.

In the individually uniformly spiteful model, for each player $i$, let $m_{i}=\operatorname{argmin}_{j \neq i} v_{j}$ and $v_{i}^{\prime}=\frac{v_{i}+\alpha_{i} v_{m_{i}}}{1+\alpha_{i}}$. The value $v_{i}^{\prime}$ is referred to as player $i$ 's virtual value. We have the following theorem.

THEOREM 2. The revenue of the second-price mechanism at any undominated strategy profile is at least the second highest virtual value, and this lower bound is tight.

To prove Theorem 2, the lemma below, proved in the appendix, characterizes the players' sets of undominated strategies.

LEMMA 1. For each player $i$, a strategy $b_{i}$ is undominated if and only if $b_{i} \geq v_{i}^{\prime}$.

That is, with spitefulness, a player will not bid anything lower than a convex combination of his own true value and the lowest one among all other players. This lower bound of his bid is determined by his exchange rate and may be lower than his true value.

Theorem 2 follows directly from Lemma 1.
Proof of TheOrem 2. For any undominated strategy profile $b$, the revenue is the second highest in $b$, which is at least the second highest in $\left(v_{i}^{\prime}\right)_{i \in[n]}$, since by Lemma 1, $b_{i} \geq v_{i}^{\prime}$ for each player $i$. Moreover, this lower bound is tight when $b_{i}=v_{i}^{\prime}$ for each $i$.

We denote the lower bound in Theorem 2 by $\operatorname{rev}(2 n d P)$. Notice that when $n=2, \operatorname{rev}(2 n d P)$ is at least the second highest (i.e., the smaller) true value of the players; while when $n \geq 3$, it is at most the second highest true value. To see more clearly how it compares with the mechanism's revenue when there is no externality, without loss of generality we assume $v_{1} \leq v_{2} \leq \cdots \leq v_{n}$. Accordingly, $m_{1}=2, m_{i}=1$ for any $i \neq 1$, the second highest true value is $v_{n-1}$, and $\operatorname{rev}(2 n d P)$ is the second highest in $T=\left\{\frac{v_{1}+\alpha_{1} v_{2}}{1+\alpha_{1}}\right\} \cup\left\{\frac{v_{i}+\alpha_{i} v_{1}}{1+\alpha_{i}}\right\}_{i \neq 1}$. We have the following corollary.

Corollary 1. As a function of the profile of exchange rates $\left(\alpha_{1}, \ldots, \alpha_{n}\right), \operatorname{rev}(2 n d P)$

1. is continuous on $(0,1]^{n}$;

2. is decreasing when $n \geq 3$ and increasing when $n=2$;

3. goes to $v_{n-1}$ when all $\alpha_{i}$ 's go to 0 , goes to $\frac{v_{n-1}+v_{1}}{2}$ when $n \geq 3$ and all $\alpha_{i}$ 's go to 1 , and goes to $\frac{v_{1}+v_{2}}{2}$ when $n=2$ and both $\alpha_{i}$ 's go to 1 ; and

4. is also continuous at $\left(\alpha_{1}, \ldots, \alpha_{n}\right)=(0, \ldots, 0)$.

Proof. Property 1 is true since all the $v_{i}^{\prime}$ 's are continuous. To see why Property 2 is true, notice that $\frac{v_{i}+\alpha_{i} v_{1}}{1+\alpha_{i}}$ is decreasing in $\alpha_{i}$ for any $i \neq 1$, and $\frac{v_{1}+\alpha_{1} v_{2}}{1+\alpha_{1}}$ is increasing in $\alpha_{1}$. Because

$$
\begin{aligned}
& \frac{v_{1}+\alpha_{1} v_{2}}{1+\alpha_{1}} \leq \frac{v_{1}+v_{2}}{2}, \quad \frac{v_{1}+v_{2}}{2} \leq \frac{v_{2}+\alpha_{2} v_{1}}{1+\alpha_{2}} \\
& \text { and } \quad \frac{v_{1}+v_{2}}{2} \leq \frac{v_{1}+v_{i}}{2} \leq \frac{v_{i}+\alpha_{i} v_{1}}{1+\alpha_{i}} \quad \forall i>2
\end{aligned}
$$

we have that $\frac{v_{1}+\alpha_{1} v_{2}}{1+\alpha_{1}}$ is the smallest in $T$. Accordingly, when $n \geq 3$, the second highest value in $T$ is the same as the second highest value in $\left(\frac{v_{i}+\alpha_{i} v_{1}}{1+\alpha_{i}}\right)_{i \neq 1}$, which is decreasing in the profile $\left(\alpha_{1}, \ldots, \alpha_{n}\right)$. When $n=2$, the second highest value in $T$ is $\frac{v_{1}+\alpha_{1} v_{2}}{1+\alpha_{1}}$, which is increasing in the profile $\left(\alpha_{1}, \alpha_{2}\right)$.

Property 3 holds by continuity, and Property 4 holds because $v_{n-1}$ is exactly the revenue when there is no externality (that is, when each player reports his true value).

We say that the players have symmetric externality if there exists $\alpha$ such that $\alpha_{i}=\alpha$ for each player $i$. When this is the case, we further have the following corollary, whose proof is omitted.

COROllary 2. When the players have symmetric externality, $\operatorname{rev}(2 n d P)=\frac{v_{n-1}+\alpha v_{1}}{1+\alpha}$ when $n \geq 3$, and $\operatorname{rev}(2 n d P)=$ $\frac{v_{1}+\alpha v_{2}}{1+\alpha}$ when $n=2$.

\section{OUR THIRD RESULT}

Now, a natural question raises: if a player knows that his opponents' bids are lower bounded as described above, can he further refine his undominated strategies? In this section, 
we answer this question by fully characterizing the players' strategies surviving such a 2 -step elimination procedure.

More precisely, the solution concept used below is two-step elimination of weakly dominated strategies. That is, starting from the strategy set $S_{i}$ for each player $i$, all players eliminate all of their weakly dominated strategies; and then, in the new game where the strategy set of each player $i$ is his set of surviving strategies, all players again eliminate all of their weakly dominated strategies. A strategy $s_{i}$ is level-2 undominated if it survives such a two-step elimination procedure. (For a thorough discussion about iterated elimination of dominated strategies, see, e.g., [39].)

In the individually uniformly spiteful model, assume there is a unique player $i^{*}$ such that $v_{i^{*}}^{\prime}=\max _{i} v_{i}^{\prime}$ : in particular, this is true when the players are in a generic position.

THEOREM 3. The revenue of the second-price mechanism at any level-2 undominated strategy profile is at least $v_{i^{*}}^{\prime}$, and this lower bound is tight.

Theorem 3 follows directly from the following lemma, which is proved in the appendix.

Lemma 2. For each player $i$, a strategy $b_{i}$ is level-2 undominated if and only if $b_{i} \geq v_{i^{*}}^{\prime}$.

We denote the lower bound in Theorem 3 by $\operatorname{rev}^{(2)}(2 n d P)$ : that is, $\operatorname{rev}^{(2)}(2 n d P)=v_{i^{*}}^{\prime}$. Again, assuming without loss of generality $v_{1} \leq v_{2} \leq \cdots \leq v_{n}$, we have the following corollary.

Corollary 3. As a function of $\left(\alpha_{1}, \ldots, \alpha_{n}\right), \operatorname{rev}^{(2)}(2 n d P)$

1. is continuous and decreasing on $(0,1]^{n}$;

2. goes to $\frac{v_{n}+v_{1}}{2}$ when all $\alpha_{i}$ 's go to 1 , and goes to $v_{n}$ when all $\alpha_{i}$ 's go to 0 ; and

3. is discontinuous at $\left(\alpha_{1}, \ldots, \alpha_{n}\right)=(0, \ldots, 0)$.

In particular, notice that when all $\alpha_{i}$ 's become arbitrarily close to 0 but are still positive, the revenue of the secondprice mechanism under level-2 undominated strategies becomes arbitrarily close to the highest true value. However, when there is no externality, the revenue is the second highest true value (as is well known). Thus, when the players further refine their strategies from their undominated strategies, the existence of externality makes a big difference for the revenue of the second-price mechanism.

What if the players continue refining their strategies based on level-2 undominated strategies? Technically, one can define $k$-step elimination of weakly dominated strategies and level- $k$ undominated strategies. However, they will not make a difference here: it is not hard to verify that no strategy can be further eliminated from level-2 undominated strategies, thus the revenue guaranteed by the second-price mechanism under level- $k$ undominated strategies with $k>2$ is still $\operatorname{rev}^{(2)}(2 n d P)$. Finally, we have the following corollary.

COROllary 4. When the players have symmetric externality, $\operatorname{rev}^{(2)}(2 n d P)=\frac{v_{n}+\alpha v_{1}}{1+\alpha}$.

\section{OUR FOURTH RESULT}

When the players have incomplete information, we consider the Light-Bayesian Setting:

- The true value of each player $i, v_{i}$, is independently drawn from a distribution $\mathcal{D}_{i}$. Without loss of generality, $\mathcal{D}_{i}$ has support $T_{i}=\left[\underline{a}_{i}, \bar{a}_{i}\right]$ with $\underline{a}_{i} \geq 0$, and the probability density function of $\mathcal{D}_{i}$ is positive on $T_{i}$. Let $\mathcal{D}=\times_{i} \mathcal{D}_{i}$ and $\mathcal{D}_{-i} \triangleq \times_{j \neq i} \mathcal{D}_{j}$ for each $i$.

- Each player $i$ individually knows his own true value, utility-exchange rates, and $\mathcal{D}_{-i}$.

- The auctioneer has no information about $\mathcal{D}$ or the utility-exchange rates of the players.

For a player $i$ to determine whether a strategy $s_{i}$ is dominated by another strategy $s_{i}^{\prime}$, he need not only know his own true value $v_{i}$, but also the others' true value subprofile $v_{-i}$. This is not a problem if the auction is of complete information, but some care is needed when $i$ only knows $\mathcal{D}_{-i}$.

\section{Revenue under non-Bayesian Undominated Strategies.}

Before defining our new solution concept for Bayesian settings, let us first consider an existing notion of weak domination in auctions of incomplete information and with externality [19]. For any player $i$ and value $v_{i} \in T_{i}$, a strategy $s_{i}$ is weakly dominated by another strategy $s_{i}^{\prime}$ under $v_{i}$ if, for every value subprofile $v_{-i} \in T_{-i}, s_{i}$ is weakly dominated by $s_{i}^{\prime}$ when the true value profile is $\left(v_{i}, v_{-i}\right) .^{5}$ Since this notion does not depend on the distribution $\mathcal{D}$, if a strategy $s_{i}$ is not weakly dominated by any other strategy under $v_{i}$, we say that $s_{i}$ is non-Bayesian undominated under $v_{i}$. In the individually uniformly spiteful model, our Proposition 1 below fully characterizes each player's non-Bayesian undominated strategies in the second-price mechanism. The proof is similar to that of Lemma 1 and thus omitted.

Proposition 1. For any player $i$ and value $v_{i} \in T_{i}$, a strategy $b_{i}$ is non-Bayesian undominated under $v_{i}$ if and only if $b_{i} \geq \frac{v_{i}+\alpha_{i} \min _{j \neq i} \underline{a}_{j}}{1+\alpha_{i}}$.

For any profile of reals $b$, let $\operatorname{Second}(b)$ be the second highest value in $b$. For any distribution $\mathcal{D}$, the expected revenue that the second-price mechanism guarantees under non-Bayesian undominated strategies, denoted by

$\operatorname{rev}_{\text {non } B}(2 n d P)$, is $\mathbb{E}_{\left(v_{1}, \ldots, v_{n}\right)}$ Second $\left(\left(\frac{v_{i}+\alpha_{i} \min _{j \neq i} \underline{a}_{j}}{1+\alpha_{i}}\right)_{i \in[n]}\right)$.

It is not hard to see that $\operatorname{rev}_{n o n}(2 n d P) \geq \frac{\mathbb{E} \operatorname{Second}\left(\left(v_{i}\right)_{i \in[n]}\right)}{2}$ $\forall n \geq 2$ and $\operatorname{rev}_{\text {non } B}(2 n d P) \leq \mathbb{E} \operatorname{Second}\left(\left(v_{i}\right)_{i \in[n]}\right) \forall n \geq 3$, where $\mathbb{E} \operatorname{Second}\left(\left(v_{i}\right)_{i \in[n]}\right)$ is the expected revenue without externality.

Moreover, when there are two players $j$ and $j^{\prime}$ such that $\underline{a}_{j}=\underline{a}_{j^{\prime}}=0$, we have

$$
\operatorname{rev}_{\text {non } B}(2 n d P)=\underset{\left(v_{1}, \ldots, v_{n}\right)}{\mathbb{E}} \operatorname{Second}\left(\left(\frac{v_{i}}{1+\alpha_{i}}\right)_{i \in[n]}\right) .
$$

That is, even if $v_{j}$ and $v_{j^{\prime}}$ are very high with probability close to 1 , the expected revenue only depends on their smallest possible value (i.e., 0). With symmetric externality, we

\footnotetext{
${ }^{5}$ The definition in [19] is slightly different: it does not require the utility of $s_{i}^{\prime}$ be strictly larger than that of $s_{i}$ in any case.
} 
further have

$$
\operatorname{rev}_{\text {non } B}(2 n d P)=\frac{1}{1+\alpha} \cdot \underset{\left(v_{1}, \ldots, v_{n}\right)}{\mathbb{E}} \operatorname{Second}\left(\left(v_{i}\right)_{i \in[n]}\right) .
$$

Proposition 1 shows that, if the players do not know the distributions of each other and only know the lower bounds of their supports, then the revenue guaranteed by the secondprice mechanism is diluted by the smallest value in the support of every player's distribution, and in the worst case it can be a half of the expected revenue when there is no externality.

When a player $i$ does know $\mathcal{D}_{-i}$, it is natural that he will reason about his strategies based on this information. Below, we provide a new solution concept to formalize this reasoning.

\section{Revenue under Bayesian Undominated Strategies.}

Our solution concept, implementation in Bayesian undominated strategies, generalizes the classical notion of implementation in undominated strategies [27] to the GSU model and the light-Bayesian settings.

For any player $i$, let $u_{i}\left(s_{i}, s_{-i} ; v_{i}, v_{-i}\right)$ be the utility of $i$ under strategy profile $\left(s_{i}, s_{-i}\right)$ and true value profile $\left(v_{i}, v_{-i}\right)$. A strategy $s_{i}$ is weakly Bayesian dominated by another strategy $s_{i}^{\prime}$ under $v_{i}$ if

(a) $\forall s_{-i} \in S_{-i}$,

$\mathbb{E}_{v_{-i} \sim \mathcal{D}_{-i}} u_{i}\left(s_{i}, s_{-i} ; v_{i}, v_{-i}\right) \leq \mathbb{E}_{v_{-i} \sim \mathcal{D}_{-i}} u_{i}\left(s_{i}^{\prime}, s_{-i} ; v_{i}, v_{-i}\right) ;$ and

(b) $\exists s_{-i} \in S_{-i}$ such that

$\mathbb{E}_{v_{-i} \sim \mathcal{D}_{-i}} u_{i}\left(s_{i}, s_{-i} ; v_{i}, v_{-i}\right)<\mathbb{E}_{v_{-i} \sim \mathcal{D}_{-i}} u_{i}\left(s_{i}^{\prime}, s_{-i} ; v_{i}, v_{-i}\right)$.

When the distribution $\mathcal{D}$ is clear from the context, we may write $\mathbb{E}_{v_{-i}} u_{i}(\cdot)$ instead of $\mathbb{E}_{v_{-i} \sim \mathcal{D}_{-i}} u_{i}(\cdot)$. Notice that player $i$ can indeed make the comparisons in (a) and (b), because he knows $\mathcal{D}_{-i}$.

If $s_{i} \in S_{i}$ is not weakly Bayesian dominated by any $s_{i}^{\prime} \in$ $S_{i}$ under $v_{i}$, then $s_{i}$ is Bayesian undominated under $v_{i}$. A Bayesian strategy of player $i$ is a function mapping $T_{i}$ to $S_{i} .{ }^{6}$ Such a strategy $\boldsymbol{s}_{i}$ is Bayesian undominated if, for each $v_{i} \in T_{i}, \boldsymbol{s}_{i}\left(v_{i}\right)$ is Bayesian undominated under $v_{i}$.

The intuition behind weak Bayesian domination is that, as in any other notion of domination, a player $i$ does not need to believe that his opponents are rational, and considers it possible for them to use arbitrary strategies no matter what their true values are. Thus, seeing a particular strategy subprofile $s_{-i}$ being used does not give player $i$ any posterior information about $v_{-i}$, and from his point of view, $v_{-i}$ is still distributed according to $\mathcal{D}_{-i}$. Accordingly, player $i$ 's perceived utility under strategy profile $\left(s_{i}, s_{-i}\right)$ is $\mathbb{E}_{v_{-i}} u_{i}\left(s_{i}, s_{-i} ; v_{i}, v_{-i}\right)$.

At the highest level, a Bayesian undominated strategy for a player $i$ is any strategy that is "not blatantly stupid for $i$ to play in light of his knowledge of $\mathcal{D}_{-i}$ and his exchange rates'. Our notion of implementation is then very robust, as it ensures that a desirable outcome occurs for any possible profile of such non-stupid strategies.

\footnotetext{
${ }^{6}$ In general, a Bayesian strategy maps player $i$ 's possible types to strategies. Thus, strictly speaking, it should map $T_{i} \times[0,1]^{n-1}$ (i.e., the set of possible values and exchange rates of $i$ ) to $S_{i}$. However, since only player $i$ 's true value is drawn from a distribution, for simplicity we define Bayesian strategies over player $i$ 's possible values only. Similarly, we write player $i$ 's utility as $u_{i}\left(s_{i}, s_{-i} ; v_{i}, v_{-i}\right)$ instead of $u_{i}\left(s_{i}, s_{-i} ; v_{i}, v_{-i} ; \alpha_{i 1}, \ldots, \alpha_{i n}\right)$.
}

In the individually uniformly spiteful model, for each player $i$ and value $v_{i}$, let $m_{i}^{\prime}=\underset{j \neq i}{\operatorname{argmin}} \underset{v_{j} \sim \mathcal{D}_{j}}{\mathbb{E}} v_{j}$ and $g_{i}\left(v_{i}\right)=\frac{v_{i}+\alpha_{i} \mathbb{E} v_{m_{i}^{\prime}}}{1+\alpha_{i}}$. We have the following.

THEOREM 4. The expected revenue of the second-price mechanism under Bayesian undominated strategies is at least

$$
\underset{\left(v_{1}, \ldots, v_{n}\right)}{\mathbb{E}} \operatorname{Second}\left(\left(g_{i}\left(v_{i}\right)\right)_{i \in[n]}\right),
$$

and this lower bound is tight.

Theorem 4 follows directly from Lemma 3 below, whose proof is provided in the appendix.

LemMa 3. For any player $i$, a Bayesian strategy $\boldsymbol{b}_{i}$ is Bayesian undominated if and only if $\boldsymbol{b}_{i}\left(v_{i}\right) \geq g_{i}\left(v_{i}\right)$ for each $v_{i} \in T_{i}$.

Notice that for a player $i$ to compute his undominated strategies, he does not even need to know $\mathcal{D}_{-i}$ : it is sufficient that he knows the expected values of his opponents.

Let $\operatorname{rev}_{B}(2 n d P)=\mathbb{E}_{\left(v_{1}, \ldots, v_{n}\right)} \operatorname{Second}\left(\left(g_{i}\left(v_{i}\right)\right)_{i \in[n]}\right)$. When the players have symmetric externality and their true values are i.i.d., we have

$$
\begin{aligned}
\operatorname{rev}_{B}(2 n d P) & =\underset{\left(v_{1}, \ldots, v_{n}\right)}{\mathbb{E}} \operatorname{Second}\left(\left(\frac{v_{i}+\alpha \mathbb{E} v_{1}}{1+\alpha}\right)_{i \in[n]}\right) \\
& =\underset{\left(v_{1}, \ldots, v_{n}\right)}{\mathbb{E}} \frac{\operatorname{Second}\left(\left(v_{i}\right)_{i \in[n]}\right)+\alpha \mathbb{E} v_{1}}{1+\alpha} \\
& =\frac{\mathbb{E}_{\left(v_{1}, \ldots, v_{n}\right)} \operatorname{Second}\left(\left(v_{i}\right)_{i \in[n]}\right)+\alpha \mathbb{E} v_{1}}{1+\alpha} .
\end{aligned}
$$

Similar to what we have seen before, this revenue goes to the expected revenue with no externality when $\alpha$ goes to 0 , and goes to the average of the two when $\alpha$ goes to 1 .

Following Theorem 4, it is not hard to see that

$$
\operatorname{rev}_{B}(2 n d P) \geq \operatorname{rev}_{\text {nonB }}(2 n d P)
$$

for all $\mathcal{D}$ and $\alpha_{i}$ 's. In the worst case (e.g., when all exchange rates are 1 and when there are two players whose values are 0 with probability 1$), \operatorname{rev}_{B}(2 n d P)$ may be as low as $\mathbb{E} \operatorname{Second}\left(\left(v_{i}\right)_{i \in[n]}\right) / 2$. However, different from $\operatorname{rev}_{\text {non } B}(2 n d P)$ which is upper bounded by $\mathbb{E} \operatorname{Second}\left(\left(v_{i}\right)_{i \in[n]}\right)$ when $n \geq 3$, $\operatorname{rev}_{B}(2 n d P)$ may actually be strictly larger than $\mathbb{E} \operatorname{Second}\left(\left(v_{i}\right)_{i \in[n]}\right)$.

As an example where $\operatorname{rev}_{B}(2 n d P)>\mathbb{E} \operatorname{Second}\left(\left\{v_{i}\right\}_{i \in[n]}\right)$, consider the case where $n=3$, each player's value is 0 with probability 0.99 and 100 with probability 0.01 , and $\alpha_{i}=$ $1 / 2$ for each $i$. We have $\mathbb{E} \operatorname{Second}\left(\left\{v_{i}\right\}_{i \in[n]}\right) \approx 0.03$ and $\operatorname{rev}_{B}(2 n d P) \approx 0.35$. Moreover, $\operatorname{rev}_{\text {non } B}(2 n d P) \approx 0.02$.

Furthermore, as an example where

$$
\operatorname{rev}_{B}(2 n d P)<\mathbb{E} \operatorname{Second}\left(\left(v_{i}\right)_{i \in[n]}\right),
$$

consider the case where $n=9$, all players' values are uniform from $[0,100]$, and $\alpha_{1}=\cdots=\alpha_{n}=1 / 2$. We have $\mathbb{E} \operatorname{Second}\left(\left\{v_{i}\right\}_{i \in[n]}\right)=80$ and $\operatorname{rev}_{B}(2 n d P)=\frac{80+50 / 2}{3 / 2}=70$. Moreover, $\operatorname{rev}_{n o n B}(2 n d P)=160 / 3$.

In general, the relation between $\operatorname{rev}_{B}(2 n d P)$ and $\mathbb{E} \operatorname{Second}\left(\left(v_{i}\right)_{i \in[n]}\right)$ depends on the relation between the $(n-$ 1)st order statistics and the expectations of the $\mathcal{D}_{i}$ 's, which is beyond the scope of this paper. 


\section{Remark.}

We believe the characterization of Bayesian undominated strategies provided in Lemma 3 to be of interest too, in light of both the centrality of the second-price mechanism in the auction literature and the fact that so little is known about the general spiteful-utility model, whether in undominated strategies, at Bayesian Nash equilibrium, or under other solution concepts.

One might also consider two-step (or more generally, $k$ step) elimination of dominated strategies in Bayesian auctions with externality. However, the revenue of the secondprice mechanism under this solution concept will be much harder to analyze than with complete information. Indeed, in Bayesian auctions a player only knows a distribution over possible sets of surviving strategies of the other players, and can only refine his own set of surviving strategies based on this distribution. We leave the analysis of the second-price mechanism under this solution concept as an open problem.

\section{RECURSIVE EXTERNALITY}

In the last secion, we briefly discuss an extension of our model, which defines the players' utilities recursively. For any player $i$, player $j \neq i$ and $k \geq 1$, the level- $k$ exchange rate of $i$ about $j, \alpha_{i j}^{k}$, is such that $\alpha_{i j}^{1} \in(0,1]$ and $\alpha_{i j}^{k} \in$ $\left(0, \alpha_{i j}^{k-1}\right]$ for any $k>1$. Given an outcome $\omega$, each player i's level-0 utility, $u_{i}^{0}(\omega)$, is defined to be his classical utility $c u_{i}(\omega)$. Recursively, for each $k \geq 1$, each player $i$ 's level- $k$ utility, $u_{i}^{k}(\omega)$, is defined to be $-\sum_{j \neq i} \alpha_{i j}^{k} u_{j}^{k-1}(\omega)$. Player $i$ 's utility is $u_{i}(\omega)=\sum_{k>0} u_{i}^{k}(\omega)$. That is, player $i$ cares about not only the other players' classical utilities, but also the external utilities they get from their opponents' classical utilities (i.e., their level-1 utilities), the external utilities they get from their opponents' level-1 utilities (i.e., their level-2 utilities), etc. However, player $i$ cares less and less about the others' level- $k$ utilities as $k$ increases, which is reflected by the non-increasing sequence $\left(\alpha_{i j}^{1}, \alpha_{i j}^{2}, \ldots\right)$ for each $j \neq i$.

We say the players have persistent externality if for each player $i$ and $j \neq i$, there exists $\alpha_{i j} \in(0,1]$ such that $\alpha_{i j}^{k}=$ $\alpha_{i j}$ for all $k \geq 1$. With persistent externality, it is easy to see that

$$
\begin{aligned}
u_{i}(\omega) & =\sum_{k \geq 0} u_{i}^{k}(\omega)=u_{i}^{0}(\omega)-\sum_{k \geq 1} \sum_{j \neq i} \alpha_{i j} u_{j}^{k-1}(\omega) \\
& =u_{i}^{0}(\omega)-\sum_{j \neq i} \alpha_{i j} \sum_{k \geq 0} u_{j}^{k}(\omega) \\
& =u_{i}^{0}(\omega)-\sum_{j \neq i} \alpha_{i j} u_{j}(\omega)
\end{aligned}
$$

which coincides with the recursive interdependent utility studied in [3], except that in [3] the players are altruistic instead of spiteful.

Let $A$ be the $n \times n$ matrix where $A_{i i}=0$ for each $i$ and $A_{i j}=-\alpha_{i j}$ for each $i$ and $j \neq i, u^{0}(\omega)=\left(u_{1}^{0}(\omega), \ldots, u_{n}^{0}(\omega)\right)^{T}$, and $u(\omega)=\left(u_{1}(\omega), \ldots, u_{n}(\omega)\right)^{T}$. We have $u(\omega)=u^{0}(\omega)+$ $A u(\omega)$. If the matrix $I-A$ is strictly diagonally dominant, namely, $\sum_{j \neq i} \alpha_{i j}<1$ for each player $i$, then it is invertible and each $u_{i}(\omega)$ has a unique closed-form solution which is a linear combination of the players' classical utilities: that is, $u(w)=(I-A)^{-1} u^{0}(w)$. However, different from [3] where $(I-A)^{-1}$ has all entries non-negative and thus the closedform utility functions are still altruistic among all players, in our model, $(I-A)^{-1}$ may have both positive and negative entries off the diagonal, showing that recursive spitefulness may actually lead to altruism among some players. ${ }^{7}$ Notice that this will never happen when $n=2$.

We leave it as an open problem to characterize the conditions under which recursive spitefulness leads to spitefulness among all players. All of our results continue to hold in these circumstances.

\section{References}

[1] J. Aseff and H. Chade. An optimal auction with identity-dependent externalities. RAND Journal of Economics, 39(3):731-746, 2008.

[2] M. Babaioff, R. Kleinberg, and C. H. Papadimitriou. Congestion games with malicious players. In Proceedings of the 8th ACM Conference on Electronic Commerce (EC 'O7), pages 103-112, 2007.

[3] T. C. Bergstrom. Systems of benevolent utility functions. Journal of Public Economic Theory, 1(1):71-100, 1999.

[4] S. Bhattacharya, D. Korzhyk, and V. Conitzer. Computing a profit-maximizing sequence of offers to agents in a social network. In Proceedings of the 8th international conference on Internet and Network Economics (WINE '12), pages 482-488, 2012.

[5] F. Bloch. Sequential formation of coalitions in games with externalities and fixed payoff division. Games and Economic Behavior, 14(1):90-123, 1996.

[6] F. Bloch and M. Jackson. The formation of networks with transfers among players. Journal of Economic Theory, 133(1):83-110, 2007.

[7] F. Brandt, T. Sandholm, and Y. Shoham. Spiteful bidding in sealed-bid auctions. In Proceedings of IJCAI'07, pages 1207-1214, 2007.

[8] J. Bulow, M. Huang, and P. Klemperer. Toeholds and takeovers. Journal of Political Economy, 107:427-454, 1999.

[9] B. Caillaud and P. Jéhiel. Collusion in auctions with externalities. RAND Journal of Economics, 29(4):680$702,1998$.

[10] T. Calvo-Armengol and M. Jackson. Like father, like son: network externalities, parent-child correlation in behavior, and social mobility. American Economic Journal: Microeconomics, 1(1):124-150, 2009.

[11] P. Chen. The effects of altruism and spite on games. $\mathrm{PhD}$ thesis, University of Southern California, October 2011.

[12] P. Chen and D. Kempe. Altruism, selfishness, and spite in traffic routing. In Proceedings of the 9th ACM conference on Electronic Commerce (EC '08), pages 140-149, 2008.

${ }^{7}$ As an example, let $n=3$ and
$A=\left[\begin{array}{ccc}0 & -1 / 10 & -1 / 2 \\ -1 / 100 & 0 & -1 / 3 \\ -1 / 4 & -1 / 10 & 0\end{array}\right]$. 
[13] V. Conitzer and T. Sandholm. Computing optimal outcomes under an expressive representation of settings with externalities. Journal of Computer and System Sciences (JCSS), Special Issue devoted to Knowledge Representation and Reasoning, 78(1):2-14, 2012.

[14] F. Constantin, M. Rao, D. C. Parkes, and C. Huang. On expressing value externalities in position auctions. In Sixth Workshop on Ad Auctions (at EC '10), 2010.

[15] G. Deltas. Determining damages from the operation of bidding rings: an analysis of the post-auction "knockout" sale. Economic Theory, 19:243-269, 2002.

[16] R. Engelbrecht-Wiggans. Auctions with priceproportional benefits to bidders. Games and Economic Behavior, 6:339-346, 1994.

[17] M. Engers and B. McManus. Charity auctions. 2004. Memo.

[18] D. Ettinger. Efficiency in auctions with crossholdings. Economics Letters, 80:1-7, 2003.

[19] A. Fiat, A. Karlin, E. Koutsoupias, and A. Vidali. Approaching Utopia: Strong truthfulness and externalityresistant mechanisms. In Proceedings of the 4 th Conference on Innovations in Theoretical Computer Science (ITCS '13), pages 221-230, 2013.

[20] S. M. G. Aggarwal, J. Feldman and M. Pál. Sponsored search auctions with Markovian users. In Proceedings of the 4th Workshop on Internet and Network Economics (WINE '08), pages 621-628, 2008.

[21] S. Gasgupta and K. Tsui. Auctions with crossshareholdings. Economic Theory, 24:163-194, 2004.

[22] A. Ghosh and M. Mahdian. Charity auctions on social networks. In Proceedings of the 19th ACM-SIAM Symposium on Discrete Algorithms (SODA '08), pages 1019-1028, 2008.

[23] A. Ghosh and A. Sayedi. Expressive auctions for externalities in online advertising. In 5th Workshop on $\mathrm{Ad}$ Auctions (at EC' '09), 2009.

[24] I. Giotis and A. R. Karlin. On the equilibria and efficiency of the GSP mechanism in keyword auctions with externalities. In Proceedings of the 4th Workshop on Internet and Network Economics (WINE '08), pages 629-638, 2008.

[25] J. K. Goeree, E. Maasland, S. Onderstal, and J. L. Turner. How (not) to raise money. Journal of Political Economy, 113(4):897-918, 2005.

[26] R. Gomes, N. Immorlica, and V. Markakis. Externalities in keyword auctions: An empirical and theoretical assessment. In Fifth Workshop on Ad Auctions (at EC '09), 2009.

[27] M. Jackson. Implementation in undominated actions: A look at bounded mechanisms. The Review of Economic Studies, 59(4):757-775, 1992.

[28] P. Jehiel and B. Moldovanu. Auctions with downstream interaction among buyers. RAND Journal of Economics, 31:768-791, 2000.
[29] P. Jehiel, B. Moldovanu, and E. Stacchetti. How (not) to sell nuclear weapons. American Economic Review, 86(4):814-829, 1996.

[30] P. Jehiel, B. Moldovanu, and E. Stacchetti. Multidimensional mechanism design for auctions with externalities. Journal of Economic Theorey, 85:258-283, 1999.

[31] S. E. Jeong. Multidimensional second-price and english auctions. Job Market Paper, 2015.

[32] D. Kempe and M. Mahdian. A cascade model for externalities in sponsored search. In Proceedings of the 4 th Workshop on Internet and Network Economics (WINE '08), pages 585-596, 2008.

[33] P. Krysta, T. Michalak, T. Sandholm, and M. Wooldridge. Combinatorial auctions with externalities (extended abstract). In Proceedings of the 9th International Joint Conference on Autonomous Agents and Multi-Agent Systems (AAMAS '10), pages 10-14, 2010.

[34] J. O. Ledyard. Public goods: A survey of experimental research. In J. H. Kagel and A. E. Roth, editors, The Handbook of Experimental Economics, pages 111-193. Princeton University Press, 1997.

[35] D. K. Levine. Modeling altruism and spitefulness in experiments. Review of Economic Dynamics, 1(3):593$622,1998$.

[36] J. Lu. Optimal auctions with asymmetric financial externalities. Games and Economic Behavior, 74(2):561575,2012 .

[37] E. Maasland and S. Onderstal. Auctions with financial externalities. Economic Theory, 32(3):551-574, 2007.

[38] I. Macho-Stadler, D. Pérez-Castrillo, and D. Wettstein. Sharing the surplus: An extension of the Shapley value for environments with externalities. Journla of Economic Theory, 135(1):339-356, 2007.

[39] M. Osborne and A. Rubinstein. A Course in Game Theory. MIT Press, 1994.

[40] D. Parkes and T. Sandholm. Optimize-and-dispatch architecture for expressive Ad auctions. In First Workshop on Sponsored Search Auctions (at EC '05), 2005.

[41] D. H. Reiley, S. Li, and R. A. Lewis. Northern exposure: A field experiment measuring externalities between search advertisements. In Proceedings of the ACM Conference on Electronic Commerce (EC'10), pages 297-304, 2010.

[42] A. Roth. The price of malice in linear congestion games. In Proceedings of the 4 th Workshop on Internet and Network Economics (WINE '08), pages 118-125, 2008.

[43] P. Tang and T. Sandholm. Optimal auctions for spiteful bidders. In Proceedings of the Twenty-Sixth AAAI Conference on Artificial Intelligence (AAAI), 2012.

[44] G. D. Varma. Standard auctions with identitydependent externalities. RAND Journal of Economics, 33:689-708, 2002. 
[45] S. Yi. Stable coalition structures with externalities. Games and Economic Behavior, 20(2):201-237, 1997.

\section{APPENDIX}

\section{Proofs of Theorem 1 and Lemmas 1, 2, and 3}

Theorem 1. (restated) For any $n \geq 2$ and $P>0$, in mechanism $M_{P}$, it is strictly dominant for each player to announce 1; and the revenue of $M_{P}$ under the strategy profile $(1,1, \ldots, 1)$ is at least $P$.

Proof. For any player $i \notin\{1,2\}$ and strategy subprofile $b_{-i}$, notice that the only difference between the outcomes of strategy profiles $\left(1, b_{-i}\right)$ and $\left(0, b_{-i}\right)$ is that, in the former player $i$ gets a payment equal to 1 , while in the latter he gets 0 . Indeed, for each player $j \notin\{1,2, i\}, j$ 's price only depends on $b_{j}$; and the prices of players 1 and 2 only depend on $b_{1}$ and $b_{2}$. Accordingly, $c u_{i}\left(1, b_{-i}\right)-c u_{i}\left(0, b_{-i}\right)=1$ and, for each $j \neq i, c u_{j}\left(1, b_{-i}\right)=c u_{j}\left(0, b_{-i}\right)$. Thus

$$
\begin{aligned}
& u_{i}\left(1, b_{-i}\right)-u_{i}\left(0, b_{-i}\right) \\
= & \left(c u_{i}\left(1, b_{-i}\right)-\sum_{j \neq i} \alpha_{i j} c u_{j}\left(1, b_{-i}\right)\right) \\
& -\left(c u_{i}\left(0, b_{-i}\right)-\sum_{j \neq i} \alpha_{i j} c u_{j}\left(0, b_{-i}\right)\right) \\
= & c u_{i}\left(1, b_{-i}\right)-c u_{i}\left(0, b_{-i}\right)=1>0,
\end{aligned}
$$

and it is strictly dominant for player $i$ to announce 1 .

For player 1 and any strategy subprofile $b_{-1}$, if $b_{2}=0$ then, similar as above, we have $c u_{1}\left(1, b_{-1}\right)=1, c u_{1}\left(0, b_{-1}\right)=$ 0 , and for each $i \neq 1, c u_{i}\left(1, b_{-1}\right)=c u_{i}\left(0, b_{-1}\right)=b_{i}$. Thus

$$
\begin{aligned}
& u_{1}\left(1, b_{-1}\right)-u_{1}\left(0, b_{-1}\right) \\
= & c u_{1}\left(1, b_{-1}\right)-c u_{1}\left(0, b_{-1}\right)=1>0 .
\end{aligned}
$$

If $b_{2}=1$, then by announcing 0 player 1 enables player 2 to get a payment equal to $\frac{P+n}{\ell}$, while he himself gets 0 . Thus

$$
\begin{aligned}
u_{1}\left(0, b_{-1}\right) & =c u_{1}\left(0, b_{-1}\right)-\sum_{i \neq 1} \alpha_{1 i} c u_{i}\left(0, b_{-1}\right) \\
& =0-\alpha_{12} \cdot \frac{P+n}{\ell}-\sum_{i \neq 1,2} \alpha_{1 i} b_{i} \\
& \leq-P-n-\sum_{i \neq 1,2} \alpha_{1 i} b_{i} .
\end{aligned}
$$

If player 1 announces 1 instead, then he pays $P+n-1$ and player 2 gets $\frac{1}{2}$. Thus

$$
\begin{aligned}
u_{1}\left(1, b_{-1}\right) & =c u_{1}\left(1, b_{-1}\right)-\sum_{i \neq 1} \alpha_{1 i} c u_{i}\left(1, b_{-1}\right) \\
& =-P-n+1-\frac{\alpha_{12}}{2}-\sum_{i \neq 1,2} \alpha_{1 i} b_{i} .
\end{aligned}
$$

By Equations 2 and 3, when $b_{2}=1$,

$$
u_{1}\left(1, b_{-1}\right)-u_{1}\left(0, b_{-1}\right) \geq 1-\frac{\alpha_{12}}{2} \geq \frac{1}{2}>0 .
$$

By Equations 1 and 4, it is strictly dominant for player 1 to announce 1.
Next, for player 2 and any strategy subprofile $b_{-2}$, if player 2 announces 0 , then his utility is

$$
u_{2}\left(0, b_{-2}\right)=c u_{2}\left(0, b_{-2}\right)-\sum_{i \neq 2} \alpha_{2 i} c u_{i}\left(0, b_{-2}\right)=-\sum_{i \neq 2} \alpha_{2 i} b_{i} .
$$

If player 2 announces 1 while $b_{1}=0$, then player 2 gets $\frac{P+n}{\ell}$ and player 1 gets $0=b_{1}$, thus

$$
\begin{aligned}
u_{2}\left(1, b_{-2}\right) & =c u_{2}\left(1, b_{-2}\right)-\sum_{i \neq 2} \alpha_{2 i} c u_{i}\left(1, b_{-2}\right) \\
& =\frac{P+n}{\ell}-\sum_{i \neq 2} \alpha_{2 i} b_{i} \\
& >-\sum_{i \neq 2} \alpha_{2 i} b_{i}=u_{2}\left(0, b_{-2}\right) .
\end{aligned}
$$

If player 2 announces 1 while $b_{1}=1$, then player 1 pays $P+n-1$ and player 2 gets $\frac{1}{2}$, thus

$$
\begin{aligned}
u_{2}\left(1, b_{-2}\right) & =c u_{2}\left(1, b_{-2}\right)-\sum_{i \neq 2} \alpha_{2 i} c u_{i}\left(1, b_{-2}\right) \\
& =\frac{1}{2}+\alpha_{21} \cdot(P+n-1)-\sum_{i \neq 1,2} \alpha_{2 i} b_{i} \\
& >-\sum_{i \neq 1,2} \alpha_{2 i} b_{i} \geq-\sum_{i \neq 2} \alpha_{2 i} b_{i} \\
& =u_{2}\left(0, b_{-2}\right),
\end{aligned}
$$

where the inequalities are because $\alpha_{21} \geq 0$. By Equations 5 and 6 , it is strictly dominant for player 2 to announce 1 .

In sum, the strategy profile $s=(1,1, \ldots, 1)$ is strictly dominant. It is easy to see that the revenue of $M_{P}$ at $s$ is

$$
(P+n-1)-\frac{1}{2}-\sum_{i \neq 1,2} b_{i}=P+n-\frac{3}{2}-(n-2)>P,
$$

and Theorem 1 holds.

Lemma 1. (restated) For each player $i$, a strategy $b_{i}$ is undominated if and only if $b_{i} \geq v_{i}^{\prime}$.

Proof. We first show that

$$
\text { if } b_{i}<v_{i}^{\prime} \text { then } b_{i} \text { is weakly dominated by } v_{i}^{\prime} \text {. }
$$

To do so, arbitrarily fix a strategy subprofile $b_{-i}$. If player $i$ gets the good under both $\left(b_{i}, b_{-i}\right)$ and $\left(v_{i}^{\prime}, b_{-i}\right)$, then under both strategy profiles his price is $\max _{j \neq i} b_{j}$ and all other players' prices are 0 . Thus $c u_{i}\left(b_{i}, b_{-i}\right)=c u_{i}\left(v_{i}^{\prime}, b_{-i}\right)=v_{i}-$ $\max _{j \neq i} b_{j}$ and $c u_{j}\left(b_{i}, b_{-i}\right)=c u_{j}\left(v_{i}^{\prime}, b_{-i}\right)=0$ for any $j \neq i$. Accordingly,

$$
\begin{aligned}
u_{i}\left(v_{i}^{\prime}, b_{-i}\right) & =c u_{i}\left(v_{i}^{\prime}, b_{-i}\right)-\alpha_{i} \sum_{j \neq i} c u_{j}\left(v_{i}^{\prime}, b_{-i}\right) \\
& =c u_{i}\left(b_{i}, b_{-i}\right)-\alpha_{i} \sum_{j \neq i} c u_{j}\left(b_{i}, b_{-i}\right) \\
& =u_{i}\left(b_{i}, b_{-i}\right) .
\end{aligned}
$$

If player $i$ gets the good in neither $\left(b_{i}, b_{-i}\right)$ nor $\left(v_{i}^{\prime}, b_{-i}\right)$, then the winner $w$ is the same under both strategy profiles. Furthermore, if

$$
v_{i}^{\prime} \leq \max _{j \neq w, i} b_{j},
$$

then under both strategy profiles the winner's price is $\max _{j \neq w, i} b_{j}$ and all other players' prices are 0 . Thus 
$c u_{w}\left(b_{i}, b_{-i}\right)=c u_{w}\left(v_{i}^{\prime}, b_{-i}\right)=v_{w}-\max _{j \neq w, i} b_{j}$ and $c u_{j}\left(b_{i}, b_{-i}\right)=c u_{j}\left(v_{i}^{\prime}, b_{-i}\right)=0$ for all $j \neq w$. Accordingly, we again have

$$
u_{i}\left(v_{i}^{\prime}, b_{-i}\right)=u_{i}\left(b_{i}, b_{-i}\right) .
$$
but

If player $i$ gets the good in neither $\left(b_{i}, b_{-i}\right)$ nor $\left(v_{i}^{\prime}, b_{-i}\right)$,

$$
v_{i}^{\prime}>\max _{j \neq w, i} b_{j},
$$

then $w$ 's price is $v_{i}^{\prime}$ under $\left(v_{i}^{\prime}, b_{-i}\right)$ and $\max _{j \neq w} b_{j}$ under $\left(b_{i}, b_{-i}\right)$. Since $v_{i}^{\prime}>b_{i}$ by assumption, we have $v_{i}^{\prime}>\max \left\{b_{i}, \max _{j \neq w, i} b_{j}\right\}=\max _{j \neq w} b_{j}$. Thus

$$
c u_{w}\left(v_{i}^{\prime}, b_{-i}\right)=v_{w}-v_{i}^{\prime}<v_{w}-\max _{j \neq w} b_{j}=c u_{w}\left(b_{i}, b_{-i}\right) .
$$

Moreover, $c u_{j}\left(b_{i}, b_{-i}\right)=c u_{j}\left(v_{i}^{\prime}, b_{-i}\right)=0$ for all $j \neq w$. Accordingly,

$$
\begin{aligned}
u_{i}\left(v_{i}^{\prime}, b_{-i}\right) & =-\alpha_{i} c u_{w}\left(v_{i}^{\prime}, b_{-i}\right) \\
& >-\alpha_{i} c u_{w}\left(b_{i}, b_{-i}\right)=u_{i}\left(b_{i}, b_{-i}\right) .
\end{aligned}
$$

The last case we need to consider is when player $i$ does not get the good under $\left(b_{i}, b_{-i}\right)$ but gets it under $\left(v_{i}^{\prime}, b_{-i}\right)$. Let $w$ be the winner under $\left(b_{i}, b_{-i}\right)$ and $p_{w}$ his price. We have

$$
b_{i} \leq \max _{j \neq w} b_{j}=p_{w} \leq b_{w}=\max _{j \neq i} b_{j} \leq v_{i}^{\prime},
$$

where the first inequality is because $w \neq i$ and the last one is because $i$ is the highest bidder in $\left(v_{i}^{\prime}, b_{-i}\right)$. Thus

$$
\begin{aligned}
u_{i}\left(b_{i}, b_{-i}\right) & =-\alpha_{i} c u_{w}\left(b_{i}, b_{-i}\right)=-\alpha_{i}\left(v_{w}-p_{w}\right) \\
& \leq-\alpha_{i}\left(v_{m_{i}}-v_{i}^{\prime}\right) \\
& =-\alpha_{i}\left[v_{m_{i}}-\frac{v_{i}+\alpha_{i} v_{m_{i}}}{1+\alpha_{i}}\right] \\
& =\frac{\alpha_{i}\left(v_{i}-v_{m_{i}}\right)}{1+\alpha_{i}}
\end{aligned}
$$

where the first equality is because $c u_{j}\left(b_{i}, b_{-i}\right)=0$ for any $j \neq w$, and the inequality is because $v_{w} \geq \min _{j \neq i} v_{j}=v_{m_{i}}$ and $p_{w} \leq v_{i}^{\prime}$. Moreover,

$$
\begin{aligned}
u_{i}\left(v_{i}^{\prime}, b_{-i}\right) & =c u_{i}\left(v_{i}^{\prime}, b_{-i}\right)=v_{i}-b_{w} \geq v_{i}-v_{i}^{\prime} \\
& =v_{i}-\frac{v_{i}+\alpha_{i} v_{m_{i}}}{1+\alpha_{i}}=\frac{\alpha_{i}\left(v_{i}-v_{m_{i}}\right)}{1+\alpha_{i}},
\end{aligned}
$$

where the first equality is because $c u_{j}\left(v_{i}^{\prime}, b_{-i}\right)=0$ for any $j \neq i$, the second equality is because the price of $i$ under $\left(v_{i}^{\prime}, b_{-i}\right)$ is $\max _{j \neq i} b_{j}=b_{w}$, and the inequality is because $b_{w} \leq v_{i}^{\prime}$. By Equations 10 and 11, we have

$$
u_{i}\left(v_{i}^{\prime}, b_{-i}\right) \geq u_{i}\left(b_{i}, b_{-i}\right)
$$

in this case.

Combining Equations 7, 8, 9 and 12, we have that $b_{i}$ is weakly dominated by $v_{i}^{\prime}$, as we wanted to show. It remains to prove that,

for any strategy $b_{i} \geq v_{i}^{\prime}, b_{i}$ is not weakly dominated by any other strategy $b_{i}^{\prime}$.

To see why this is true, arbitrarily fix a strategy $b_{i}^{\prime}$. If $b_{i}^{\prime}<b_{i}$, then let $b_{-i}$ be a strategy subprofile such that (1) $b_{w}>b_{i}$ where $w=\operatorname{argmax}_{j \neq i} b_{j}$, and (2) $\max _{j \neq i, w} b_{j} \leq b_{i}^{\prime}$. That is, the highest bid of all the other players is larger than $b_{i}$, but the second highest is at most $b_{i}^{\prime}$. Accordingly, player $w$ gets the good under both $\left(b_{i}, b_{-i}\right)$ and $\left(b_{i}^{\prime}, b_{-i}\right)$, with price $b_{i}$ in the former and $b_{i}^{\prime}$ in the latter. All other players always have price 0 and classical utility 0 . Thus

$$
\begin{aligned}
u_{i}\left(b_{i}, b_{-i}\right) & =-\alpha_{i} c u_{w}\left(b_{i}, b_{-i}\right)=-\alpha_{i}\left(v_{w}-b_{i}\right) \\
& >-\alpha_{i}\left(v_{w}-b_{i}^{\prime}\right) \\
& =-\alpha_{i} c u_{w}\left(b_{i}^{\prime}, b_{-i}\right)=u_{i}\left(b_{i}^{\prime}, b_{-i}\right),
\end{aligned}
$$

and $b_{i}$ is not weakly dominated by $b_{i}^{\prime}$.

If $b_{i}^{\prime}>b_{i}$, then let $b_{-i}$ be such that $\max _{j \neq i, m_{i}} b_{j} \leq b_{i}<$ $b_{m_{i}}<b_{i}^{\prime}$. By construction, player $m_{i}$ gets the good at price $b_{i}$ under $\left(b_{i}, b_{-i}\right)$, and player $i$ gets the good at price $b_{m_{i}}$ under $\left(b_{i}^{\prime}, b_{-i}\right)$. Again, all players who do not get the good have classical utility 0 . Thus

$$
\begin{aligned}
u_{i}\left(b_{i}, b_{-i}\right) & =-\alpha_{i} c u_{m_{i}}\left(b_{i}, b_{-i}\right)=-\alpha_{i}\left(v_{m_{i}}-b_{i}\right) \\
& \geq-\alpha_{i}\left(v_{m_{i}}-v_{i}^{\prime}\right)=-\alpha_{i}\left[v_{m_{i}}-\frac{v_{i}+\alpha_{i} v_{m_{i}}}{1+\alpha_{i}}\right] \\
& =\frac{\alpha_{i}\left(v_{i}-v_{m_{i}}\right)}{1+\alpha_{i}}
\end{aligned}
$$

and

$$
\begin{aligned}
u_{i}\left(b_{i}^{\prime}, b_{-i}\right) & =c u_{i}\left(b_{i}^{\prime}, b_{-i}\right)=v_{i}-b_{m_{i}} \\
& <v_{i}-v_{i}^{\prime}=v_{i}-\frac{v_{i}+\alpha_{i} v_{m_{i}}}{1+\alpha_{i}} \\
& =\frac{\alpha_{i}\left(v_{i}-v_{m_{i}}\right)}{1+\alpha_{i}},
\end{aligned}
$$

where the inequalities are because $v_{i}^{\prime} \leq b_{i}<b_{m_{i}}$. Combining these two inequalities, we again have

$$
u_{i}\left(b_{i}, b_{-i}\right)>u_{i}\left(b_{i}^{\prime}, b_{-i}\right),
$$

and $b_{i}$ is not weakly dominated by $b_{i}^{\prime}$.

By Equations 13 and 14, $b_{i}$ is not weakly dominated by any other strategy $b_{i}^{\prime}$, as we wanted to show. In sum, $b_{i}$ is undominated if and only if $b_{i} \geq v_{i}^{\prime}$, and Lemma 1 holds.

Lemma 2. (restated) For each player $i$, a strategy $b_{i}$ is level-2 undominated if and only if $b_{i} \geq v_{i^{*}}^{\prime}$.

Proof. For each player $i$, let $S_{i}^{\prime}$ be his set of strategies surviving the first-step elimination of weakly dominated strategies. By Lemma 1, we have $S_{i}^{\prime}=\left\{b_{i} \mid b_{i} \geq v_{i}^{\prime}\right\}$.

First, for any player $i \neq i^{*}$ and any strategy $b_{i} \in\left[v_{i}^{\prime}, v_{i^{*}}^{\prime}\right)$, we show that

$b_{i}$ is weakly dominated in the game with strategy space

$$
S^{\prime}=S_{1}^{\prime} \times S_{2}^{\prime} \times \cdots \times S_{n}^{\prime} .
$$

To do so, let $b_{i}^{\prime}$ be a strategy such that

$$
b_{i}^{\prime} \in\left(\max _{j \neq i^{*}} v_{j}^{\prime}, v_{i^{*}}^{\prime}\right) \cap\left(b_{i}, v_{i^{*}}^{\prime}\right) .
$$

Notice that, since $i^{*}$ is unique, we have $\max _{j \neq i *} v_{j}^{\prime}<v_{i^{*}}^{\prime}$ and such a $b_{i}^{\prime}$ exists. Arbitrarily fix a strategy subprofile $b_{-i} \in S_{-i}^{\prime}$. Since $b_{i^{*}} \in S_{i^{*}}^{\prime}$, we have $b_{i^{*}} \geq v_{i^{*}}^{\prime}>b_{i}^{\prime}>b_{i}$, and player $i$ gets the good in neither $\left(b_{i}, b_{-i}\right)$ nor $\left(b_{i}^{\prime}, b_{-i}\right)$. Thus the winner of the good under both strategy profiles is the same, denoted by player $w$ (who may or may not be player $\left.i^{*}\right)$. Below, we compare $u_{i}\left(b_{i}, b_{-i}\right)$ and $u_{i}\left(b_{i}^{\prime}, b_{-i}\right)$ by distinguishing two cases for $b_{-i}$.

When $b_{-i}=v_{-i}^{\prime}$, we have that: (1) $w=i^{*} ;(2)$ the price of $w$ under $\left(b_{i}, b_{-i}\right)$ is

$$
p_{w}=\max _{j \neq w} b_{j}=\max \left\{b_{i}, \max _{j \neq i^{*}, i} v_{j}^{\prime}\right\}=\max \left\{b_{i}, \max _{j \neq i^{*}} v_{j}^{\prime}\right\},
$$


where the third equality is because $v_{i}^{\prime} \leq b_{i}$; and (3) the price of $w$ under $\left(b_{i}^{\prime}, b_{-i}\right)$ is

$$
p_{w}^{\prime}=b_{i}^{\prime}
$$

since $b_{i}^{\prime}>\max _{j \neq i^{*}} v_{j}^{\prime} \geq \max _{j \neq i^{*}, i} v_{j}^{\prime}=\max _{j \neq i^{*}, i} b_{j}$. Because $b_{i}^{\prime}>b_{i}$ and $b_{i}^{\prime}>\max _{j \neq i^{*}} v_{j}^{\prime}$ by definition, we have $p_{w}<p_{w}^{\prime}$, and thus

$$
c u_{i^{*}}\left(b_{i}, b_{-i}\right)=v_{i^{*}}-p_{w}>v_{i^{*}}-p_{w}^{\prime}=c u_{i^{*}}\left(b_{i}^{\prime}, b_{-i}\right) .
$$

Accordingly,

$$
\begin{aligned}
u_{i}\left(b_{i}, b_{-i}\right) & =-\alpha_{i} c u_{i^{*}}\left(b_{i}, b_{-i}\right) \\
& <-\alpha_{i} c u_{i^{*}}\left(b_{i}^{\prime}, b_{-i}\right)=u_{i}\left(b_{i}^{\prime}, b_{-i}\right) .
\end{aligned}
$$

For any other $b_{-i} \in S_{-i}^{\prime}$, we have $p_{w} \leq p_{w}^{\prime}$, since $b_{i}^{\prime}>$ $b_{i}$ and all of the other players' bids remain the same under the two strategy profiles. Accordingly, $c u_{w}\left(b_{i}, b_{-i}\right) \geq$ $c u_{w}\left(b_{i}^{\prime}, b_{-i}\right)$ and

$$
\begin{aligned}
u_{i}\left(b_{i}, b_{-i}\right) & =-\alpha_{i} c u_{w}\left(b_{i}, b_{-i}\right) \\
& \leq-\alpha_{i} c u_{w}\left(b_{i}^{\prime}, b_{-i}\right)=u_{i}\left(b_{i}^{\prime}, b_{-i}\right) .
\end{aligned}
$$

By Equations 15 and 16, we have that $b_{i}$ is weakly dominated by $b_{i}^{\prime}$ in the game with strategy space $S^{\prime}$, as we wanted to show.

Next, for any player $i \neq i^{*}$ and any strategy $b_{i} \geq v_{i^{*}}^{\prime}$, we show that

$$
\begin{gathered}
b_{i} \text { is not weakly dominated in the game } \\
\text { with strategy space } S^{\prime} \text {. }
\end{gathered}
$$

We distinguish two cases.

On the one hand, for any strategy $b_{i}^{\prime} \in\left[v_{i}^{\prime}, b_{i}\right)$, consider the strategy subprofile $b_{-i}$ such that $b_{i^{*}}>b_{i}$ and $b_{j}=v_{j}^{\prime}$ for any $j \notin\left\{i, i^{*}\right\}$. Clearly, $b_{-i} \in S_{-i}^{\prime}$. Because

$$
b_{i^{*}}>b_{i} \geq v_{i^{*}}^{\prime}>\max _{j \neq i^{*}, i} v_{j}^{\prime}=\max _{j \neq i^{*}, i} b_{j},
$$

player $i^{*}$ gets the good under both strategy profile $\left(b_{i}, b_{-i}\right)$ and $\left(b_{i}^{\prime}, b_{-i}\right)$. Moreover, his price under the former is

$$
p_{i^{*}}=\max \left\{b_{i}, \max _{j \neq i^{*}, i} b_{j}\right\}=b_{i},
$$

and that under the latter is

$$
p_{i^{*}}^{\prime}=\max \left\{b_{i}^{\prime}, \max _{j \neq i^{*}, i} b_{j}\right\}=\max \left\{b_{i}^{\prime}, \max _{j \neq i^{*}, i} v_{j}^{\prime}\right\}<b_{i}=p_{i^{*}} .
$$

Accordingly, $c u_{i^{*}}\left(b_{i}, b_{-i}\right)=v_{i^{*}}-p_{i^{*}}<v_{i^{*}}-p_{i^{*}}^{\prime}=c u_{i^{*}}\left(b_{i}^{\prime}, b_{-i}\right)$, and

$$
\begin{aligned}
u_{i}\left(b_{i}, b_{-i}\right) & =-\alpha_{i} c u_{i^{*}}\left(b_{i}, b_{-i}\right) \\
& >-\alpha_{i} c u_{i^{*}}\left(b_{i}^{\prime}, b_{-i}\right)=u_{i}\left(b_{i}^{\prime}, b_{-i}\right) .
\end{aligned}
$$

Thus, for any strategy $b_{i}^{\prime} \in\left[v_{i}^{\prime}, b_{i}\right), b_{i}^{\prime}$ does not weakly dominate $b_{i}$ in the game with strategy space $S^{\prime}$.

On the other hand, for any strategy $b_{i}^{\prime}>b_{i}$, consider the strategy subprofile $b_{-i}$ such that $b_{m_{i}} \in\left(b_{i}, b_{i}^{\prime}\right)$ and $b_{j}=v_{j}^{\prime}$ for any $j \notin\left\{i, m_{i}\right\}$. Again we have $b_{-i} \in S_{-i}^{\prime}$. Because

$$
b_{m_{i}}>b_{i} \geq v_{i^{*}}^{\prime}=\max _{j} v_{j}^{\prime} \geq \max _{j \neq m_{i}, i} v_{j}^{\prime}=\max _{j \neq m_{i}, i} b_{j},
$$

player $m_{i}$ gets the good under strategy profile $\left(b_{i}, b_{-i}\right)$ with price $b_{i}$. Accordingly,

$$
\begin{aligned}
u_{i}\left(b_{i}, b_{-i}\right) & =-\alpha_{i} c u_{m_{i}}\left(b_{i}, b_{-i}\right)=-\alpha_{i}\left(v_{m_{i}}-b_{i}\right) \\
& >-\alpha_{i}\left(v_{m_{i}}-v_{i}^{\prime}\right)=-\alpha_{i}\left[v_{m_{i}}-\frac{v_{i}+\alpha_{i} v_{m_{i}}}{1+\alpha_{i}}\right] \\
& =\frac{\alpha_{i}\left(v_{i}-v_{m_{i}}\right)}{1+\alpha_{i}},
\end{aligned}
$$

where the inequality is because $b_{i} \geq v_{i^{*}}^{\prime}>v_{i}^{\prime}$. Furthermore, since $b_{i}^{\prime}>b_{m_{i}}$, player $i$ gets the good under strategy profile $\left(b_{i}^{\prime}, b_{-i}\right)$ with price $b_{m_{i}}$. Thus

$$
\begin{aligned}
u_{i}\left(b_{i}^{\prime}, b_{-i}\right) & =c u_{i}\left(b_{i}^{\prime}, b_{-i}\right)=v_{i}-b_{m_{i}}<v_{i}-b_{i} \\
& <v_{i}-v_{i}^{\prime}=v_{i}-\frac{v_{i}+\alpha_{i} v_{m_{i}}}{1+\alpha_{i}} \\
& =\frac{\alpha_{i}\left(v_{i}-v_{m_{i}}\right)}{1+\alpha_{i}}<u_{i}\left(b_{i}, b_{-i}\right)
\end{aligned}
$$

and such a $b_{i}^{\prime}$ does not weakly dominate $b_{i}$ in the game with strategy space $S^{\prime}$.

By Equations 17 and 18, $b_{i}$ is not weakly dominated in the game with strategy space $S^{\prime}$, as we wanted to show. Accordingly, for any player $i \neq i^{*}$, a strategy $b_{i}$ is level-2 undominated if and only if $b_{i} \geq v_{i^{*}}^{\prime}$.

Finally, it remains to show that for player $i^{*}$ and any strategy $b_{i^{*}} \geq v_{i^{*}}^{\prime}$,

$b_{i^{*}}$ is not weakly dominated by any strategy $b_{i *}^{\prime}$ in the game with strategy space $S^{\prime}$.

For any strategy $b_{i^{*}}^{\prime} \in\left[v_{i^{*}}^{\prime}, b_{i^{*}}\right)$, the analysis is very similar to the deduction of Inequality 17 (under the case where $i \neq$ $i^{*}, b_{i} \geq v_{i^{*}}^{\prime}$, and $\left.b_{i}^{\prime} \in\left[v_{i}^{\prime}, b_{i}\right)\right)$. For any strategy $b_{i^{*}}^{\prime}>b_{i^{*}}$, the analysis is very similar to the deduction of Inequality 18 (under the case where $i \neq i^{*}, b_{i} \geq v_{i^{*}}^{\prime}$, and $b_{i}^{\prime}>b_{i}$ ). Thus the detailed analysis for this part is omitted.

In sum, Lemma 2 holds.

Lemma 3. (restated) For any player $i$, a Bayesian strategy $\boldsymbol{b}_{i}$ is Bayesian undominated if and only if $\boldsymbol{b}_{i}\left(v_{i}\right) \geq g_{i}\left(v_{i}\right)$ for each $v_{i} \in T_{i}$.

Proof. It suffices to prove that for any $v_{i} \in T_{i}$, a strategy $b_{i}$ is Bayesian undominated under $v_{i}$ if and only if $b_{i} \geq$ $g_{i}\left(v_{i}\right)$. To see why this is true, notice that for any strategy $b_{i}$ and strategy subprofile $b_{-i}$, the mechanism's outcome under $\left(b_{i}, b_{-i}\right)$ does not depend on the true values. Let $w$ be the winner under this strategy profile and $p_{w}$ his price. We have that for any value subprofile $v_{-i}, u_{i}\left(b_{i}, b_{-i} ; v_{i}, v_{-i}\right)=v_{i}-p_{w}$ if $w=i$, and $u_{i}\left(b_{i}, b_{-i} ; v_{i}, v_{-i}\right)=-\alpha_{i} c u_{w}\left(b_{i}, b_{-i} ; v_{i}, v_{-i}\right)=$ $-\alpha_{i}\left(v_{w}-p_{w}\right)$ otherwise. Accordingly,

$$
\underset{v_{-i}}{\mathbb{E}} u_{i}\left(b_{i}, b_{-i} ; v_{i}, v_{-i}\right)=v_{i}-p_{w}
$$

if $w=i$, and

$$
\underset{v_{-i}}{\mathbb{E}} u_{i}\left(b_{i}, b_{-i} ; v_{i}, v_{-i}\right)=-\alpha_{i} \underset{v_{w}}{\mathbb{E}}\left(v_{w}-p_{w}\right)=-\alpha_{i}\left(\mathbb{E} v_{w}-p_{w}\right)
$$

otherwise. That is, player $i$ 's expected utility under strategy profile $\left(b_{i}, b_{-i}\right)$ in the Bayesian auction is exactly his utility under the same strategy profile in the auction of complete information where his true value is $v_{i}$ and, for any $j \neq i$, player $j$ 's true value is $\mathbb{E} v_{j}$. Therefore $b_{i}$ is weakly Bayesian dominated under $v_{i}$ in the Bayesian auction if and only if it is weakly dominated in the auction of complete information with true value profile $\left(v_{i},\left(\mathbb{E} v_{j}\right)_{j \neq i}\right)$. By Lemma 1 , we immediately have that $b_{i}$ is Bayesian undominated under $v_{i}$ if and only if $b_{i} \geq g_{i}\left(v_{i}\right)$, and Lemma 3 holds. 